\title{
COMENTARIO:
}

\section{EL RECONOCIMIENTO JURISPRUDENCIAL DEL LITISCONSORCIO NECESARIO IMPROPIO}

\author{
Alejandro Romero SEguel ${ }^{*}$
}

DOCTRINA: La legitimación como condición de la acción, es un tema de fondo que debe apreciar el juez. No es factible declarar una nulidad de un acto o contrato en contra de terceros que no fueron parte del juicio.

La sentencia de la Corte Suprema, de 26 de abril de 2006, tiene varios méritos para el estudio del derecho procesal.

En primer lugar, constituye una auténtica pieza doctrinal sobre el contenido del derecho de acción. Con ocasión de un recurso de casación en el fondo, nuestro máximo tribunal se ha detenido a precisar una serie de cuestiones procesales sobre el derecho de acción. En primer lugar, parte por definir a la acción como un derecho subjetivo autónomo, dirigido a obtener una determinada resolución jurisdiccional favorable a la parte reclamante $\left(\mathrm{C}^{\circ} 9\right)$. Acto seguido, puntualiza la función que tiene dentro la legitimación, a la que estima como una condición de la acción.

En segundo lugar, introduce la utilización de una categoría procesal que ya estaba incorporada en nuestra realidad forense, pero sin darle su denominación propia: litisconsorcio necesario impropio.

La utilización de esta nomenclatura técnica demuestra que el derecho es un fenómeno plural que no se agota solo en el dato normativo legal. La jurisprudencia es una parte relevante, la expresión más viva de lo que es el derecho, en este caso introduciendo una nomenclatura científica que inexplicablemente no es frecuente en nuestras decisiones judiciales. En materia procesal, son muchas las reglas o decisiones jurisprudenciales que luego se han recogido como normas legales.

El poder de la jurisprudencia, de la buena jurisprudencia, radica en su capacidad para introducir instituciones jurídicas, dando dinamismo al ordenamiento. De la jurisprudencia depende, en muchas ocasiones, que se puedan incorporar instituciones que no obstante contar en el ámbito doctrinal con un rico desarrollo, hasta que no son consideradas por los jueces en sus decisiones, no pasan de meras exposiciones teóricas.

Abogado, Doctor en Derecho por la Universidad de Navarra (España). Profesor de Derecho Procesal, U. de los Andes (CHILE). Correo electrónico: aromero@uandes.cl 
En este caso estamos frente a un magnífico aporte para la utilización de categorías dogmáticas, que se adelantan a la inercia legislativa en el desarrollo de las instituciones procesales. Aunque en varias ocasiones nuestros tribunales habían sancionado implícitamente la existencia de la figura que nos ocupa, especialmente para la protección de los derechos de los terceros, en esta ocasión a la figura se le llama por su nombre técnico.

Con anterioridad a este fallo, las sentencias habían privilegiado una interpretación a través de los principios procesales, asumiendo la jurisprudencia una función de creación judicial del derecho, pero no habían querido dar el paso de hablar directamente de la figura en cuestión, seguramente para no herir la susceptibilidad de los cultores del positivismo jurídico legalista, que creen que en materia procesal solo existe lo que dice el legislador.

Muy tímidamente la doctrina de la Corte Suprema había recogido expresamente el nombre propio de esta institución, en las sentencias de fecha 25 de julio y 16 de octubre de 1941 , aunque debe reconocerse que no se trata de una voz muy difundida en nuestros fallos ${ }^{1}$.

Aunque podrían formularse varios comentarios a esta interesante decisión, nos detendremos en la declaración de los considerando decimoquinto y decimosexto, en la parte que declara no procede declarar la nulidad en contra de un tercero, que no obstante ser legitimado pasivo, no fue demandado en el juicio. Según la Corte Suprema, si el tercero legitimado no ha sido emplazado, los jueces del fondo no pueden declarar esa ineficacia jurídica, para no afectar la garantía constitucional del debido proceso.

Para llegar a la declaración anterior la sentencia acepta una distinción en torno a la legitimación. Según el número de sujetos, la doctrina distingue entre legitimación individual y legitimación conjunta. La primera es aquella que se confiere al titular de un derecho subjetivo o interés legítimo por ser titular del mismo, para poder impetrar tutela jurisdiccional sin el concurso de otros sujetos; en cambio, la legitimación conjunta es la que corresponde mancomunadamente a un grupo de personas, activa o pasivamente, dando vida al litisconsorcio necesario.

Aunque este fallo se debe sumar a otros de nuestros tribunales, que había sancionado la misma doctrina jurídica, el mérito de esta decisión radica en la utilización rigurosa de las categorías procesales para fundamentar su conclusión, al punto de utilizar explícitamente en una sentencia de la Corte Suprema la expresión litis consorcio necesario impropio, tal como se lee en el considerando decimosexto.

Cfr. RDJ, t., XXXIX, sec. $1^{\text {a }}$, pp. 127 y 276; en igual sentido, C. Ap. de Valparaíso, 30 de julio de 1965, RDJ, t., LXII, sec. 2a , p. 122, y 30 de septiembre de 1997, esta última inédita. 
También es un mérito la referencia a la garantía constitucional del debido proceso, demostrando que ella no es una fórmula vacía de contenido, la que es vinculada con instituciones procesal de gran raigambre. En efecto, en el considerando decimosexto se justifica la referencia al debido proceso expresando que "(...) en el caso sublite pudo darse lo que en doctrina se denomina litisconsorcio o acumulación subjetiva, es decir, la concurrencia de pluralidad de partes activas o pasivas. Existió tal posibilidad de un litisconsorcio pasivo necesario impropio, es decir, que la naturaleza de la relación jurídica determina que el asunto controvertido debe ser resuelto a través de una decisión única por el juez. Así la actora debió accionar no solo en contra de Cooperativa Rural Eléctrica Llanquihue Ltda.., sino que necesariamente además en contra de Ondavisión...(...) por encontrarnos ante un caso de litisconsorcio pasivo necesario".

Esta decisión demuestra que la conformación de la relación jurídica procesal no es un producto exclusivo de la ley, sino más bien una derivación de la experiencia jurídica y de las necesidades que el proceso jurisdiccional debe satisfacer. Efectivamente, la deducción de la acción en un juicio es un acto complejo, que requiere de un examen minucioso acerca de la legitimación conjunta o individual, para determinar el grado de la participación de los sujetos en un proceso determinado.

La Corte Suprema, con este fallo ha reconocido jurisprudencialmente lo que en otros ordenamientos hace bastante tiempo en una realidad positiva, al admitir que en casos concretos existe una necesidad jurídica que varios sujetos participen obligatoriamente en un proceso para poder fallar en fondo del conflicto. 